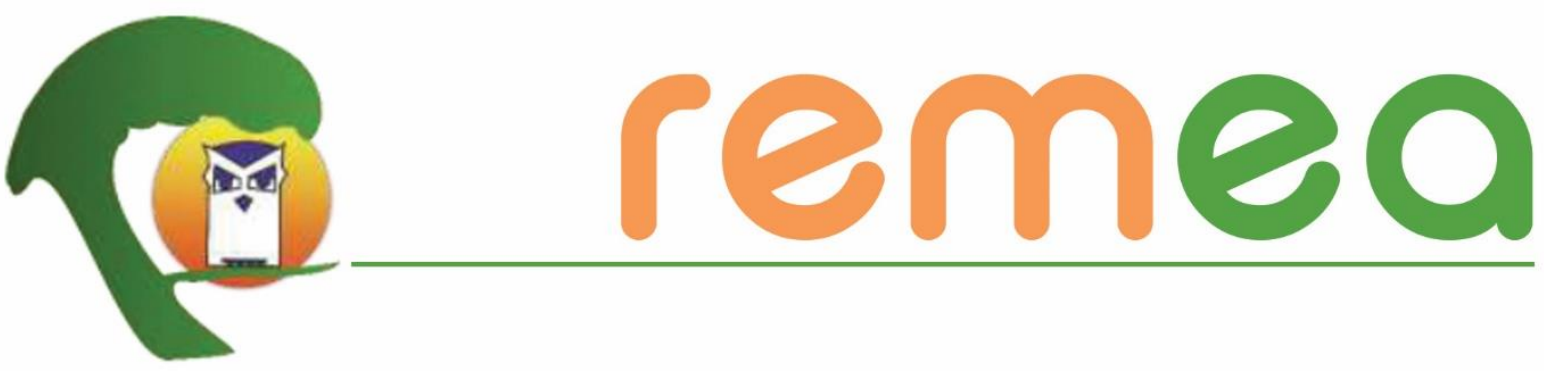

\title{
A discussão da subjetividade na produção teórica sobre Educação Ambiental e formação de professores de Biologia
}

\author{
Raquel de Oliveira Sales ${ }^{1}$ \\ Universidade Federal de Juiz de Fora - Campus Governador Valadares \\ ORCID https://orcid.org/0000-0001-9939-019X \\ Maria Gabriela Parenti Bicalho ${ }^{2}$ \\ Universidade Federal de Juiz de Fora - Campus Governador Valadares \\ ORCID https://orcid.org/0000-0002-5223-9721 \\ Thiago Martins Santos ${ }^{3}$ \\ Universidade Vale do Rio Doce - Univale \\ ORCID https://orcid.org/0000-0002-3595-4088
}

Resumo: Este trabalho apresenta resultados de uma dissertação que analisa a presença de discussões relativas à subjetividade na produção teórica sobre Educação Ambiental (EA) e formação de professores de Biologia, publicada pela Scientific Eletronic Library Online (SciELO) entre 2008 e 2018. A partir da adoção de três conjuntos de termos de busca, foram identificados 27 artigos, cuja análise revelou a presença da discussão sobre a subjetividade na proposta de associação da natureza à cultura; na adoção dos termos percepção, concepção, identidade, sentido e significado na elaboração de problemas de pesquisa; e na utilização de metodologias participativas e colaborativas. O material analisado permite identificar as discussões sobre

\footnotetext{
${ }^{1}$ Licenciada em Ciências Biológicas pela Universidade Federal de Viçosa. Especialista em Educação Ambiental pela Universidade Federal de Ouro Preto. Mestre em Ensino de Biologia pelo Mestrado Profissional em Ensino de Biologia (ProfBio) da UFJF-GV (instituição associada) e da UFMG (instituição sede), com auxílio da CAPES. Professora de Biologia do ensino médio das redes pública e privada do Vale do Aço, Minas Gerais. E-mail: raquel.osales@gmail.com

${ }^{2}$ Graduada em Psicologia pela Universidade Federal de Minas Gerais. Mestre e Doutora em Educação pela Faculdade de Educação da Universidade Federal de Minas Gerais. Professora do Curso de Medicina e do Programa de Mestrado Profissional em Ensino de Biologia da Universidade Federal de Juiz de Fora - Campus Governador Valadares. E-mail: maria.gabriela@ufjf.edu.br

${ }^{3}$ Licenciado em Ciências Biológicas pela Universidade Vale do Rio Doce. Licenciado em Pedagogia pela Universidade de Uberaba. Especialista em Educação pela Universidade Vale do Rio Verde. Mestre em Gestão Integrada do Território pela Universidade Vale do Rio Doce. Professor da Universidade Vale do Rio Doce e professor colaborador do Programa de Mestrado Profissional em Ensino de Biologia da Universidade Federal de Juiz de Fora - Campus Governador Valadares. E-mail: thiago.santos@univale.br
}

Revista Eletrônica do Mestrado em Educação Ambiental Programa de Pós-Graduação em Educação Ambiental - FURG v. 38 , n. 1, p. 158-177, jan./abr. 2021. E-ISSN: 1517-1256 
subjetividade na adoção de determinadas categorias teóricas e na utilização de metodologias participativas nas pesquisas realizadas com professores.

Palavras-chave: Educação Ambiental, Subjetividade, Formação de Professores de Biologia.

\section{La discusión de la subjetividad en la producción teórica sobre la Educación Ambiental y la formación de profesores de Biología}

Resumen: Este trabajo presenta los resultados de una disertación que analiza la presencia de discusiones sobre la subjetividad en la producción teórica sobre Educación Ambiental (EA) y Formación de Profesores de Biología, publicada por Scientific Electronic Library Online (SciELO) entre 2008 y 2018. Fueron adoptados tres conjuntos de términos de búsqueda, y luego, se identificaron 27 artículos, cuyo análisis reveló la presencia de un debate sobre la subjetividad propuesta sobre la asociación de la naturaleza a la cultura; la adopción de los términos percepción, concepción, identidad, significado y significación en la elaboración de problemas de investigación; y el uso de metodologías participativas y de colaboración. El material analizado permite identificar las discusiones sobre la subjetividad en la adopción de ciertas categorías teóricas y en el uso de metodologías participativas en la investigación con los profesores.

Palabras-clave: Educación Ambiental, Subjetividad, Formación de Profesores de Biología.

The discussion of subjectivity in the theoretical production on Environmental Education and Biology teachers' training

Abstract: This paper presents the results of a dissertation that analyzes the presence of discussions regarding subjectivity in the theoretical production on Environmental Education (EA) and Training of Biology Teachers, published by Scientific Electronic Library Online (SciELO) between 2008 and 2018. We adopted three sets of search terms and twenty-seven (27) articles were identified. The analysis revealed the presence of discussions on subjectivity in the proposed association of nature to culture; the adoption of terms such as perception, conception, identity, meaning and significance in the elaboration of research problems; and the use of participatory and collaborative methodologies. The material analyzed allows the identification of the discussions about subjectivity regarding the adoption of certain theoretical categories and on the use of participatory methodologies in research with teachers.

Keywords: Environmental Education, Subjectivity, Biology Teachers' Training

\section{Introdução}

Este trabalho apresenta resultados de uma pesquisa realizada em uma unidade do PROFBIO - Mestrado Profissional em Ensino de Biologia em Rede Nacional. O tema da investigação originou-se de reflexões da autora principal, professora de Biologia nas redes estadual e privada de um município do estado de Minas Gerais, sobre práticas docentes em Educação Ambiental (EA), especialmente voltadas para a subjetividade.

A Educação Ambiental é apresentada pela Política Nacional de Educação Ambiental PNEA (BRASIL, 1999) e pelas Diretrizes Curriculares Nacionais para a Educação Ambiental DCNEA (BRASIL, 2012) como componente essencial e permanente da educação brasileira, 
que tem como intenção central a formação de conhecimentos e valores ambientais e a construção de sociedades justas e sustentáveis. É preconizada como elemento transversal da educação escolar e as abordagens interdisciplinares são indicadas como as mais adequadas para o seu ensino. Observa-se, frequentemente, a associação da Biologia à EA, o que faz com que os professores dessa disciplina sejam convidados a participar de projetos interdisciplinares, ou mesmo "dar conta" da EA nas escolas de educação básica ${ }^{4}$ (REIGOTA, 2009). Considerando que a formação nos cursos de licenciatura em Ciências Biológicas não contempla, de modo acabado, tal demanda, justifica-se a importância da discussão da abordagem da EA no Ensino de Biologia em cursos de formação continuada.

Os documentos oficiais citados indicam o pluralismo de ideias e concepções pedagógicas como um princípio básico da EA. O estudo das diferentes vertentes da Educação Ambiental (SAUVÉ, 2008) permite observar a incorporação, a partir dos anos 1990, de discussões ligadas à subjetividade. $\mathrm{O}$ reconhecimento da relevância dos aspectos subjetivos para a compreensão das relações entre os sujeitos e o meio justificou o interesse em conhecer a abordagem dessa discussão na produção teórica relativa à Educação Ambiental no Ensino de Biologia. Espera-se, com isso, contribuir para a reflexão sobre a formação de professores de Biologia.

O objetivo geral da pesquisa foi analisar a presença de discussões relativas à subjetividade na produção teórica sobre Educação Ambiental (EA) e formação de professores de Biologia, publicada pela Scientific Eletronic Library Online (SciELO) entre 2008 e 2018. Como produto da referida pesquisa, além do Trabalho de Conclusão de Mestrado, foi elaborado um material para orientação de formação de professores em EA. A metodologia adotada foi a pesquisa bibliográfica, inicialmente baseada nos artigos do tipo estado da arte de Reigota (2007), Carvalho, Tomazello e Oliveira (2009), Carvalho e Farias (2011) e Kreuz (2018). A partir desse panorama, foram definidas as seguintes conjugações de termos para busca de artigos da SciELO entre 2008 e 2018: formação de professores e Educação Ambiental; formação de professores, Biologia e Educação Ambiental; e Educação

\footnotetext{
${ }^{4}$ Reigota (2009) destaca que é comum a EA ser confundida com o ensino de Ecologia. Embora ele ressalte que a EA não deva prescindir dos conteúdos ecológicos, afirma que, Ecologia e EA devem ser reconhecidas como campos com especificidades próprias.
} 
Ambiental e subjetividade. Foram identificados 46 artigos, 19 dos quais eliminados por falta de conexão com o tema. Portanto, a análise de 27 artigos fundamenta a discussão apresentada neste artigo.

\section{A dimensão subjetiva da Educação Ambiental}

A PNEA define a Educação Ambiental como "processos por meio dos quais o indivíduo e a coletividade constroem valores sociais, conhecimentos, habilidades, atitudes e competências voltadas para a conservação do meio ambiente, bem de uso comum do povo, essencial à sadia qualidade de vida e sua sustentabilidade" (BRASIL, 1999).

Essa definição reflete a macrovisão socioambiental de meio ambiente, construída a partir da problematização da macrovisão naturalista-conservacionista que marcou o surgimento da EA em âmbito mundial, na década de 1960 (REIGOTA, 2009; CARVALHO, 2012). A discussão da Educação Ambiental nasce, portanto, do entendimento de meio ambiente como natureza-recurso (CARVALHO, 2012) e adquire novas configurações, a partir da noção de ambiente como produto das interações dinâmicas entre o meio natural e o meio social (REIGOTA, 2009).

Sauvé (2008) analisa concepções de meio ambiente que permeiam o desenvolvimento da discussão sobre Educação Ambiental: natureza, recurso natural, biosfera, território, espaço de reivindicação de igualdade de direitos entre homens e mulheres e de problematização de realidades socioambientais, espaço no qual as relações entre pessoas e natureza são marcadas por elementos da cultura. Dessas concepções originam-se maneiras diversas de pensar e praticar a EA. Interessa-nos, neste trabalho, aquela que enfatiza a influência de aspectos subjetivos, referentes à visão de mundo e às experiências dos sujeitos acerca das questões ambientais.

A produção de Carvalho (2008) subsidia essa análise, ao propor as características básicas dos profissionais ambientais e, em particular, do educador ambiental. Adota a categoria "sujeito ecológico" como noção simbólica que emerge das relações sociais, deflagradas pelas questões ambientais e pelas trajetórias biográficas e profissionais. Esse sujeito se (re)constrói no meio social e, ao mesmo tempo, (re)organiza a sociedade. Pode ser 
visto como um tipo ideal, "capaz de encarnar os dilemas societários, éticos e estéticos configurados pela crise societária em sua tradução contracultural; tributário de um projeto de sociedade socialmente emancipada e ambientalmente sustentável" (CARVALHO, 2008, p. 56).

O sujeito ecológico pode ser um militante engajado no tempo presente, mas carrega consigo uma identidade narrativa que frequentemente remete a memórias míticas. A autora adota conceitos fortemente relacionados a aspectos subjetivos como identidade narrativa e memória, e explica que em algum momento do passado, tais pessoas perceberam o ambiente por meio de uma visão infantil ou romântica da natureza, o que os tornou sensíveis às questões ambientais. Aborda, ainda, a relação entre o sujeito ecológico e a interpretação, compreendida como "[...] processo de aprendizagem do mundo e de si mesmo e, portanto, de produção de sentidos, com base em uma permanente interação criativa entre o sujeito e o mundo" (CARVALHO, 2008, p. 78).

A produção teórica de Tuan (1980, 2005), no campo da Geografia Humana, oferece subsídios para a compreensão da importância da subjetividade na abordagem das relações humanas com o meio natural, ao defender que "[...] sem auto-compreensão não podemos esperar soluções duradouras para os problemas ambientais que, fundamentalmente, são problemas humanos" (TUAN, 1980, p. 1). O lugar (ou meio ambiente) fornece o estímulo sensorial que, ao ser percebido, dá forma às alegrias e aos ideais do sujeito que com ele se relaciona. Para Tuan, espaço e lugar não são sinônimos. O primeiro pode se transformar no segundo, mas a recíproca não é verdadeira. Compreender o lugar implica experienciá-lo, atribuindo a ele valor e significação. Tuan $(1980,2005)$ estabelece o conceito de "topofilia" como o elo afetivo entre a pessoa e o lugar ou ambiente físico. As experiências positivas e agradáveis com relação aos ambientes são topofílicas, as negativas e desagradáveis são topofóbicas.

As contribuições de Carvalho (2008) e Tuan (1980, 2005) constituem elementos de uma perspectiva de Educação Ambiental que valoriza aspectos da subjetividade. Tais aspectos são abordados com o auxílio do campo teórico-metodológico das Ciências Humanas, por meio de conceitos como experiências, memórias, valores, emoções, concepções, sentidos, significados, entre outros. Indicam a necessidade de convergência 
entre as propostas de EA e as experiências e concepções de educadores e educandos, pois as trajetórias socioambientais dos sujeitos interferem, significativamente, na forma como identificam e reagem às questões de sustentabilidade. Apresentam-se, a seguir, os resultados da pesquisa bibliográfica, buscando indicar como essa perspectiva foi abordada na produção teórica da área e identificar os caminhos desenhados para a formação de professores de Biologia no campo da Educação Ambiental.

\section{Subjetividade, Educação Ambiental e formação de professores de Biologia: o que mostram os artigos}

A partir das conjugações dos termos de busca anteriormente apresentados formação de professores e Educação Ambiental; formação de professores, Biologia e Educação Ambiental; e Educação Ambiental e subjetividade - foram identificados os trabalhos que compuseram o material analisado. Os 27 trabalhos foram produzidos por 25 primeiros autores, dentre os quais 20 autores (80\%) são doutores. Desses 25 primeiros autores, 18 (72\%) são mulheres. Quanto à vinculação do primeiro autor, são 20 instituições brasileiras e 1 portuguesa. Em relação apenas às 20 instituições brasileiras, 12 (60\%) são universidades da esfera federal. Ressalta-se, ainda, que essas 20 instituições brasileiras estão sediadas, predominantemente, na Região Sudeste (8 instituições, correspondendo a 40\%) e na Região Sul (6 instituições, correspondendo 30\%).

A análise aprofundada desses artigos permite identificar as temáticas e abordagens predominantes nas palavras-chave e no desenvolvimento dos textos.

A análise dos artigos levou ao levantamento de 59 palavras-chave ${ }^{5}$. Educação Ambiental é palavra-chave de 18 artigos e formação de professores de 13, predominância previsível, visto serem parte dos termos de busca adotados. Os termos Educação em Ciências/Ensino de Biologia/ Ensino de Ciências configuram palavras-chave de 5 artigos, o

\footnotetext{
${ }^{5}$ Inicialmente foram identificadas 66 palavras-chave. Algumas foram agrupadas por serem sinônimas ou se referirem a um mesmo grupo semântico: 1) Educação em Ciências/ Ensino de Biologia/Ensino de Ciências, 2) meio ambiente/ambiente, 3) ensino fundamental/ensino fundamental e médio/ensino médio, 4) currículo/currículos escolares, 5) cursos de licenciatura/licenciatura.
} 
que pode ser visto como reflexo da ligação da EA ao Ensino de Biologia. As demais palavraschave aparecem entre uma e três vezes e foram categorizadas em 5 grupos semânticos:

Grupo I- fundamentos metodológicos e filosóficos (20 palavras-chaves), revelam a predominância das metodologias de construção coletiva e participativa do conhecimento, como narrativa, arqueologia foucaultiana, grupo focal, investigação-ação, parceria colaborativa e teoria da atividade, Educação Ambiental Crítica, alfabetização científica.

Grupo II- meio ambiente (16 palavras-chaves), engloba os termos: meio ambiente, crise ambiental, desenvolvimento sustentável, sustentabilidade, recursos hídricos, bacia hidrográfica, planície de inundação e seca, e localização geográfica.

Grupo III- níveis de escolaridade (10 palavras-chaves), entre os quais: ensino fundamental, ensino médio, licenciatura.

Grupo IV - rotina escolar (9 palavras-chave), abrange os termos ambiente escolar, projetos escolares, cotidiano escolar, currículo.

Grupo V- conceitos ligados à discussão da subjetividade (8 palavras-chaves): trajetórias, concepções, identidades, autobiografia, concepções, discurso, representação, saberes docentes.

A análise aprofundada dos 27 artigos, sob a ótica do objetivo da pesquisa, permitiu dividi-los em quatro grupos: grupo I - Educação Ambiental e subjetividade docente (13 artigos); grupo II - Educação Ambiental, formação de professores e subjetividade (8 artigos); grupo III - estratégias didáticas para a Educação Ambiental (3 artigos); grupo IV- inserção da Educação Ambiental em cursos de licenciatura (3 artigos).

Grupo I - Educação Ambiental e subjetividade docente

Neste grupo, foram reunidos 13 artigos. Três adotam a categoria concepções para caracterizar a relação dos professores com a EA. Araújo e França (2012) analisam concepções de EA de licenciandos em Ciências Biológicas de duas instituições federais de Recife. Correia (2014) relaciona concepções e práticas de EA de futuras professoras da 
educação básica; e Araújo e Pedrosa (2014) avaliam concepções e práticas sobre desenvolvimento sustentável de professores de Biologia em formação.

Quatro artigos adotam como categorias centrais os termos ideias, representações e percepções. Inocêncio e Salvi (2017) analisam as ideias sobre Ciências, a partir da forma como os enunciados refletem as abordagens em EA. Magalhães Júnior e Tomanik (2013) trazem à tona as representações sociais sobre o meio ambiente de professores em formação continuada. Hofstatter, Oliveira e Souto (2016) debruçam-se sobre o processo social na constituição da percepção, enquanto Guimarães e Inforsato (2012) enfocam as percepções de professores de Biologia e concluintes de licenciatura em relação à EA na formação inicial.

Dois artigos relatam pesquisas que adotam a metodologia de análise de narrativas. Mendes e Vaz (2009) utilizaram a técnica do grupo focal para identificar, nas narrativas de professores, como os saberes docentes permeiam as experiências e as perspectivas em relação à EA no ensino formal. Piccinini (2011) identifica, por meio de narrativas, aspectos da consciência nas trajetórias de formação e atuação de educadores ambientais. Nos dois casos, as narrativas reforçam a ideia de que as práticas docentes sofrem influência das identidades, memórias, percepções, compreensões e concepções dos professores acerca de si mesmos e da coletividade, interferindo na forma como conduzem as atividades de EA.

Em outros dois artigos deste grupo, elementos subjetivos são identificados nos processos de construção da pesquisa. Nigro e Azevedo (2011) verificaram os objetivos do Ensino de Ciências e o grau de importância conferido à disciplina por professores. Conduziram a pesquisa de forma colaborativa, considerando as subjetividades dos envolvidos (pesquisados e pesquisadores) como condicionantes dos resultados obtidos na disciplina e, por conseguinte em EA. Machado, Marques e Silva (2016) investigam os sentidos e significados produzidos por professores sobre os termos problema e problematização na Educação em Ciências, utilizando "Situação de Estudo" (SE) ${ }^{6}$ e o tema "Ambiente e vida: o ser humano nesse contexto". Nesse artigo, os elementos subjetivos atrelam-se à elaboração da SE que se deu mediante reuniões semanais entre os integrantes

\footnotetext{
6 Situação de estudo (SE) é uma abordagem interdisciplinar e contextual, constituída de temas conceitualmente enriquecedores, a fim de que os estudantes tenham algo a dizer sobre eles. Defende-se a ideia do professor que investiga a sua prática, a qual é assentada em processos de estudos sobre determinada situação vivencial da realidade social e escolar (MACHADO, MARQUES e SILVA, 2016, p. 24).
} 
do Grupo Triádico ${ }^{7}$, durante os quais foram debatidos temas ambientais que fazem parte dos conteúdos escolares.

Os dois últimos trabalhos do grupo I abordam elementos subjetivos sob enfoques diferentes dos anteriores. Pelegrini e Vlach (2011) analisam os condicionantes da temática ambiental e ressaltam a necessidade de ampliação de sua discussão nas disciplinas ligadas às Ciências Sociais. Destacam tal ampliação como estratégia de sensibilização e compreensão da problemática ambiental.

Cremos ser desnecessário reprisar o papel que os professores têm a cumprir neste processo, especialmente na promoção de discussões em sala de aula, em torno dos aspectos envolvidos na questão ambiental, quais sejam, os de natureza política, geopolítica, social e ideológica. É preciso, talvez mais do que nunca, que haja uma ampliação da abordagem no trato da questão ambiental. (PELEGRINI e VLACH, 2011, p. 195).

Cortes Júnior e Sá (2017) estudaram o Conhecimento Pedagógico do Conteúdo $(P C K)^{8}$, mobilizado por alunos iniciantes em um mestrado em Educação em Ciências, durante a elaboração de atividades de EA. Afirmam a importância da consideração de aspectos relativos à subjetividade dos professores na EA.

A compreensão geral da EA, que envolve o conhecimento do professor, suas crenças sobre a finalidade e os objetivos do ensino de EA, caracteriza a maneira pela qual ele vai ensinar e orienta a tomada de decisões sobre a escolha de temas socioambientais, os procedimentos de ensino, as estratégias de aprendizagem, o uso de materiais didáticos e a avaliação da aprendizagem. (CORTES JUNIOR e SÁ, 2017, p. 5).

Identifica-se, nos 13 artigos deste grupo, o predomínio de categorias como concepções, representações sociais e percepções. Para coleta dos dados, foram utilizadas técnicas participativas, como grupo focal, pesquisa-ação e entrevista e, para a análise dos dados coletados, a metodologia de análise de discurso é predominante. Em geral, as concepções manifestadas pelos professores sujeitos das pesquisas são avaliadas pelos autores como concepções ingênuas e tendentes à desvinculação entre natureza e cultura.

\footnotetext{
${ }^{7}$ Grupo Triádico: designação usada pelos autores para o conjunto dos envolvidos, ou seja, professores universitários, docentes da educação básica e licenciandos.

${ }^{8}$ Os autores adotam o conceito de PCK (Pedagogical Content Knowledge) proposto por Shulman, (1986) que corresponde ao conhecimento prático que "capacita o professor a transformar um conteúdo específico em um conteúdo para ser ensinado” (CORTES JUNIOR; SÁ, 2017, p. 19).
}

Revista Eletrônica do Mestrado em Educação Ambiental Programa de Pós-Graduação em Educação Ambiental - FURG v. 38 , n. 1, p. 158-177, jan./abr. 2021. E-ISSN: 1517-1256 
Alguns trabalhos analisados estabelecem relações entre os saberes e formas de conceber dos professores e sua função de formadores na área da EA.

Grupo II - Educação Ambiental, formação de professores e subjetividade

O agrupamento dos 8 artigos do grupo II deu-se em função da ênfase na proposição de abordagens metodológicas participativas, em pesquisas sobre formação docente em EA. Apesar da variedade de atividades e temáticas adotadas, as formações têm em comum a ênfase sobre o trabalho coletivo.

Bergmann e Pedrozo (2008), Obara et al. (2009 e 2015) e Teixeira e Alves (2015) desenvolveram trabalhos em escolas públicas, usando os recursos hídricos como tema de EA. Fundamentaram-se no questionamento de concepções e práticas, buscando ampliar a visão dos atores sociais sobre bacias hidrográficas e gestão sustentável dos recursos hídricos. Abreu e Moura (2014) e Martins e Schnetzler (2018) focalizaram as mudanças de sentidos interiorizados pelos professores e as consequências disso sobre suas práticas. Os primeiros fundamentaram-se na teoria da atividade e buscaram ampliar os pontos de vista dos sujeitos. Os últimos constataram que

[...] pela socialização das experiências de ensino, os professores foram, paulatinamente, modificando suas práticas docentes, inicialmente pontuais e compartimentalizadas; no decorrer do trabalho, tais práticas foram alteradas com a inclusão de temáticas socioambientais abordadas de forma crítica, contextualizada, permanente, contínua e participativa (idem, p. 581).

Lima e Oliveira (2011) também propuseram mudanças nas concepções dos professores, enfatizando a reconstrução dos conceitos de natureza, meio ambiente e EA, a fim de promover a formação continuada. Teixeira e Alves (2015), assim como Abreu e Moura (2014) e Martins e Schnetzler (2018), desenvolveram propostas de formação continuada que, estrategicamente, utilizaram o horário de trabalho coletivo. Esse espaço escolar é institucionalizado em muitas escolas e destina-se ao planejamento, de preferência por intermédio da interação entre os docentes. Silva (2010) adota a leitura de imagens sob a perspectiva crítica da EA na coleta de dados e encontra entre os professores pesquisados concepções pragmáticas e antropocêntricas. Defende o processo interpretativo de imagens 
como instrumento para a formação de cidadãos menos ingênuos e mais críticos diante do cotidiano e, portanto, da questão ambiental, por envolver os níveis "cognitivo, afetivo e crítico" (SILVA, 2010, p. 295).

Conclui-se que, no grupo II, os artigos salientam o trabalho colaborativo como metodologia de pesquisa. Essa ênfase implica uma forma de abordar a subjetividade ligada à atividade e à profissão, na qual os professores são considerados sujeitos que se mobilizaram em relação às atividades desenvolvidas pelos pesquisadores e transformaram suas formas de conceber o meio ambiente e a Educação Ambiental.

\section{Grupo III - Estratégias didáticas para a Educação Ambiental.}

Os três artigos do grupo III apresentam diferentes possibilidades de organização do trabalho docente em Educação Ambiental. Priorizam a análise das práticas dos professores, particularmente a forma como são conduzidos os projetos, bem como as estratégias didáticas e fontes de informação por eles adotadas. De forma similar aos trabalhos do grupo anterior, as metodologias de pesquisa são de caráter participativo.

Santos e Jacobi (2011) promoveram formação continuada de professores por meio da pesquisa-ação e de projetos escolares de EA. Utilizaram diferentes estratégias para o (re)conhecimento do lugar (topofilia) e buscaram uma visão integrada da realidade, a partir das relações dialéticas entre o local e o global, inerentes à questão ambiental. Propuseram o mapeamento socioambiental como instrumento de participação da comunidade, por meio da identificação de demandas, percepções e tendências. Cavalcanti Neto e Amaral (2011) averiguaram estratégias didáticas utilizadas por professoras de Ciências nos temas ambientais e avaliaram a contribuição dessas estratégias para a implantação da Educação Ambiental Crítica. A partir dessa análise, ressaltam a sensibilização como processo pertinente à abordagem da EA no ensino.

Tozoni-Reis et al. (2013) pesquisaram as fontes de informação utilizadas pelos professores da educação básica, no processo de formação em EA. Durante a análise das estratégias para obtenção de informação, preocuparam-se com a identificação dos "condicionantes históricos dessa prática, refletindo sobre o contexto social, político, 
econômico e pedagógico do esvaziamento da dimensão intelectual do trabalho dos professores" (TOZONI-REIS et al., 2013, p. 362). Afirmam que a escolha das fontes de informação é perpassada pela subjetividade, envolvendo a percepção dos sujeitos para localizá-las e selecioná-las adequadamente, dentro do contexto da EA. Os autores observam que essa escolha orienta a prática docente.

Ao analisar as estratégias didáticas adotadas pelos professores na EA, os artigos deste grupo defendem a consideração dos docentes como sujeitos históricos e reconhecem ligações entre suas práticas e suas concepções, estratégias e aspirações.

Grupo IV - Inserção da Educação Ambiental em cursos de licenciatura

Os artigos do grupo IV analisam a presença da EA nos cursos de licenciatura. Boton et al. (2010) investigam os projetos político-pedagógicos dos cursos de licenciatura, a fim de verificar em que medida a temática meio ambiente se insere na preparação de professores. Com base nos resultados, apontam a diversidade de abordagens práticas, principalmente nos relatos de experiência dos sujeitos, que vão desde métodos de sensibilização até atividades reflexivas e problematizadoras da realidade socioambiental. Teixeira e Torales (2014) investigam ações que consideram a dimensão ambiental nos cursos de licenciatura. Concluem que o perfil político-epistemológico das disciplinas aponta que as questões ambientais migraram para a EA, mas não como disciplina específica. "Prevalece o sentido de educação ambiental afim da utopia da transformação do conhecimento e da relação entre a sociedade e a natureza" (TEIXEIRA e TORALES, 2014, p. 141).

Tozoni-Reis e Campos (2014) problematizam a formação inicial de professores em cursos de licenciatura e seus impactos sobre a abordagem da Educação Ambiental no ensino básico. Adotam como referência a Pedagogia Histórico-Crítica, "que defende que o papel da escola é a sistematização dos saberes elaborados pela cultura" (TOZONI-REIS e CAMPOS, 2014, p. 145) para analisar a política de formação de professores da educação básica nos cursos de licenciatura. Concluem que a inserção da Educação Ambiental almejada passa pela reformulação da formação dos professores, por meio da superação da racionalidade prática. Defendem a formação de um professor culto, caracterizado por uma intelectualidade crítica, 
incentivado a ser protagonista na construção e realização de um currículo escolar que reconheça as atividades do campo ambiental como espaço social institucional para formação plena.

\section{Considerações finais}

A pesquisa realizada objetivou analisar a presença das discussões sobre subjetividade, em 27 artigos que articulam discussões sobre Educação Ambiental e formação de professores de Biologia, identificados a partir de três conjuntos de termos de busca. A importância atribuída à subjetividade na EA foi reconhecida na adoção de categorias como experiência, sensibilização, reflexão, problematização, sentido, transformação, saberes, associadas à realidade socioambiental, relação sociedade, cultura e natureza. São abordagens múltiplas, fato que indica possibilidades de interdisciplinaridade, mas dificulta a comparação entre os artigos.

Do ponto de vista metodológico, destaca-se a adoção de metodologias colaborativas e participativas em pesquisas com professores, que valorizam a identificação e a transformação de concepções e práticas de Educação Ambiental: de concepções inicialmente naturalistas-conservacionistas, desconectadas dos aspectos da cultura, a concepções mais críticas, que transpõem noções simplistas de ambiente. Indicam a possibilidade de superação da visão ingênua e utilitarista de ambiente, e a consequente migração para um olhar socioambiental, que relacione subjetividade, sociedade e meio ambiente. Tais pesquisas remetem, ainda que não explicitamente, ao conteúdo das discussões sobre subjetividade, ao observar e buscar compreender os processos de transformação das concepções e práticas docentes, articulando-os a diferentes aspectos como as condições de trabalho e as formas de organização dos currículos.

As limitações da metodologia adotada na pesquisa, relatadas neste artigo, referem-se ao fato de que foram considerados apenas os artigos científicos indexados em uma base de dados (SciELO). Além disso, a busca realizada a partir das palavras-chave não permitiu identificar referências nas quais as relações entre $E A$, subjetividade e formação de professores de Biologia estão presentes no artigo, mas não foram destacadas nas palavras- 
chave. Apresenta-se como perspectiva de novas pesquisas a análise da presença de categorias ligadas à subjetividade em artigos sobre o ensino de Biologia, considerando que é a essa disciplina que se atribui, frequentemente, a responsabilidade pela abordagem das questões de Educação Ambiental. Ainda assim, pode-se afirmar a partir da análise do material utilizado nesta pesquisa que a formação de professores de Biologia para atuação em EA deve valorizar as relações dos sujeitos do processo educativo com os diferentes lugares nos quais vivem, trabalham e estudam.

Retomando a motivação inicial da primeira autora deste artigo, professora de Biologia, sobre a abordagem da EA na prática do ensino dessa disciplina, a pesquisa realizada indica a importância da consideração do caráter subjetivo dos processos de ensinoaprendizagem da $E A$, tanto na prática pedagógica quanto na produção de conhecimento. Essa abordagem da subjetividade, inseparável das questões culturais, históricas e sociais, vai ao encontro da visão do ambiente como produto das interações dinâmicas entre o meio natural e o meio social. Permite a aproximação da complexidade dos processos educacionais, ao considerar concepções, visões de mundo, sentimentos e valores dos sujeitos que ensinam e aprendem a partir de seu lugar no mundo.

Finalmente, a consideração dos aspectos subjetivos na Educação Ambiental indica a necessidade de promover formação inicial e continuada de professores de Biologia que favoreçam a identificação desses profissionais com a EA, considerando a necessária convergência entre as propostas de EA e as experiências e concepções de educadores e educandos.

\section{Referências}

ABREU, Daniela Gonçalves de; MOURA, Manoel Oriosvaldo de. Construção de instrumentos teórico-metodológicos para captar a formação de professores. Educ. Pesqui., São Paulo, v. 40, n. 2, p. 401-414, Jun. 2014. Disponível em:

$<$ http://www.scielo.br/scielo.php?script=sci arttext\&pid=S1517-

97022014000200007\&lng=en\&nrm=iso >. Acesso em: 23 Mar. 2019.

ARAUJO, Magnólia Fernandes Florêncio de; PEDROSA, Maria Arminda. Desenvolvimento sustentável e concepções de professores de biologia em formação inicial. Ens. Pesqui. Educ. Ciênc. (Belo Horizonte), Belo Horizonte, v. 16, n. 2, p. 71-84, Aug. 2014. Disponível em: 
$<$ http://www.scielo.br/scielo.php?script=sci arttext\&pid=S1983-

21172014000200071\&lng=en\&nrm=iso >. Acesso em: 23 Mar. 2019.

ARAUJO, Mônica Lopes Folena; FRANÇA, Tereza Luiza de. Concepções de Educação Ambiental de professores de biologia em formação nas universidades públicas federais do Recife. Educ. rev., Curitiba, n. 50, p. 237-252, Dec. 2013. Disponível em:

$<$ https://www.scielo.br/scielo.php?script=sci arttext\&pid=S010440602013000400015\&lng=en\&nrm=is>. Acesso em: 23 Mar. 2019.

BERGMANN, Melissa; PEDROZO, Catarina da Silva. Explorando uma bacia hidrográfica na escola: contribuições à Educação Ambiental. Ciênc. educ. (Bauru), Bauru, v. 14, n. 3, p. 537553, 2008. Disponível em:

< http://www.scielo.br/scielo.php?script=sci arttext\&pid=S1516$\underline{73132008000300011 \& \operatorname{lng}=e n \& n r m=i s o}>.23$ de março de 2019.

BOTON, Jaiane de Moraes et al. O meio ambiente como conformação curricular na formação docente. Ens. Pesqui. Educ. Ciênc. (Belo Horizonte), Belo Horizonte, v.12, n. 3, p. 4150, Dec. 2010. Disponível Acesso em: em: < http://www.scielo.br/scielo.php?script=sci arttext\&pid=S198321172010000300041\&lng=en\&nrm=iso >. Acesso em: 23 Mar. 2019.

BRASIL. Lei no 9.795, de 27 de abril de 1999. Dispõe sobre a educação ambiental, institui a Política Nacional de Educação Ambiental e dá outras providências. Disponível em: <http://www.planalto.gov.br/ccivil 03/leis//9795.htm> Acesso em: 10 de abril 2019.

BRASIL. Resolução CNE/CP no 2, de 15 de junho de 2012. Estabelece as Diretrizes Curriculares Nacionais para a Educação Ambiental. Disponível em: $<$ http://portal.mec.gov.br/index.php?option=com docman\&view=download\&alias=10988rcp002-12-pdf\&category slug=maio-2012-pdf\&ltemid=30192> Acesso em 10 de abril 2019.

CARVALHO, Isabel Cristina de Moura. A invenção do sujeito ecológico: identidades e subjetividade na formação dos educadores ambientais. In: Sato, M. e Carvalho, I. C. M. (orgs) Educação Ambiental: pesquisa e desafios. Porto Alegre, Artmed, 2008.

CARVALHO, Isabel Cristina de Moura. Educação ambiental: a formação do sujeito ecológico. 6ạ ed. São Paulo, Cortez, 2012.

CARVALHO, Isabel Cristina de Moura; FARIAS, Carmen Roselaine de Oliveira. Um balanço da produção científica em educação ambiental de 2001 a 2009 (ANPEd, ANPPAS e EPEA). Rev. Bras. Educ., Rio de Janeiro, v. 16, n. 46, p. 119-134, Apr. 2011. Disponível em: < http://www.scielo.br/scielo.php?script=sci arttext\&pid=S141324782011000100007\&lng=en\&nrm=iso >. Acesso em: 22 de mar 2019. 
CARVALHO, Luiz Marcelo de; TOMAZELLO, Maria Guiomar Carneiro; OLIVEIRA, Haydée Torres de. Pesquisa em educação ambiental: panorama da produção brasileira e alguns de seus dilemas. Cad. CEDES, Campinas, v. 29, n. 77, p. 13-27, Apr. 2009. Disponível em: <http://www.scielo.br/scielo.php?script=sci arttext\&pid=S010132622009000100002\&Ing=en\&nrm=iso >. Acesso em: 5 abril 2019.

CAVALCANTI NETO, Ana Lucia Gomes; AMARAL, Edenia Maria Ribeiro do. Ensino de ciências e educação ambiental no nível fundamental: análise de algumas estratégias didáticas. Ciênc. educ. (Bauru), Bauru, v. 17, n. 1, p. 129-144, 2011. Disponível em: $<$ http://www.scielo.br/scielo.php?script=sci arttext\&pid=S151673132011000100009\&lng=en\&nrm=iso >. Acesso em: 23 Mar. 2019.

CORREIA, Marisa Monteiro. Concepções de futuras professoras do ensino básico acerca do ambiente, da educação ambiental e das estratégias didáticas em educação ambiental. Ens. Pesqui. Educ. Ciênc. (Belo Horizonte), Belo Horizonte, v. 16, n. 1, p. 15-30, Apr. 2014. Disponível em:

< http://www.scielo.br/scielo.php?script=sci arttext\&pid=S1983-

21172014000100015\&lng=en\&nrm=iso >. Acesso em: 23 Mar. 2019.

CORTES JUNIOR, Lailton Passos; SA, Luciana Passos. Conhecimento pedagógico do conteúdo no contexto da educação ambiental: uma experiência com mestrandos em ensino de ciências. Ens. Pesqui. Educ. Ciênc. (Belo Horizonte), Belo Horizonte, v. 19, p. 1-22, 2017. Disponível em: < http://www.scielo.br/scielo.php?script=sci arttext\&pid=S198321172017000100204\&lng=en\&nrm=iso >. Acesso em: 23 Mar. 2019.

DIEGUES, Antonio Carlos. Conhecimentos, práticas tradicionais e a etnoconservação da natureza. Desenvolvimento e Meio Ambiente, v. 50, 2019. Disponível em: < https://revistas.ufpr.br/made/article/view/66617 > Acesso em: 2 Ago 2019. http://dx.doi.org/10.5380/dma.v50i0.66617.

GONZÁLEZ REY, Fernando. As categorias de sentido, sentido pessoal e sentido subjetivo: sua evolução e diferenciação na teoria histórico-cultural. Psicologia da Educação, n. 24, p. 155179, 2007. Disponível em: <http://pepsic.bvsalud.org/pdf/psie/n24/v24a11.pdf > Acesso em: 02 out 2018.

GUIMARÃES, Mauro; DE QUEIROZ, Edileuza Dias; DE OLIVEIRA PLÁCIDO, Patrícia. Reflexões sobre a pesquisa na formação de professores/educadores ambientais. Pesquisa em Educação Ambiental, v. 9, n. 1, p. 110-119, 2014. Disponível em: <http://www.periodicos.rc.biblioteca.unesp.br/index.php/pesquisa/article/view/8857> Acesso em: 25 de abril 2019. 
GUIMARÃES, Simone Sendin Moreira; INFORSATO, Edson do Carmo. A percepção do professor de Biologia e a sua formação: a Educação Ambiental em questão. Ciênc. educ. (Bauru), Bauru, v. 18, n. 3, p. 737-754, 2012. Disponível em: < http://www.scielo.br/scielo.php?script=sci arttext\&pid=S151673132012000300016\&lng=en\&nrm=iso > . Acesso em: 23 Mar. 2019.

HOFFMANN, Jussara. Avaliar para promover: as setas do caminho. $3^{\mathrm{a}}$ ed. Porto Alegre. Mediação. 2001.

HOFSTATTER, Lakshmi Juliane Vallim; OLIVEIRA, Haydée Torres de; SOUTO, Francisco José Bezerra. Uma contribuição da educação ambiental crítica para (des)construção do olhar sobre a seca no semiárido baiano. Ciênc. educ. (Bauru), v. 22, n. 3, p. 615-633, Sept. 2016. Disponível em:

$<$ http://www.scielo.br/scielo.php?script=sci arttext\&pid=S151673132016000300615\&lng=en\&nrm=iso >. Acesso em: 23 Mar. 2019.

INOCENCIO, Adalberto Ferdnando; SALVI, Rosana Figueiredo. O reverberar da crise ambiental: uma análise arqueológica dos discursos de professores de ciências. Ciênc. educ. (Bauru), Bauru, v. 23, n. 3, p. 613-624, July 2017. Disponível em:

$<$ http://www.scielo.br/scielo.php?script=sci arttext\&pid=S15163132017000300613\&lng=en\&nrm=isso>. Acesso em: 23 Mar. 2019.

KREUZ, Ângela Maria. Temas mais pesquisados em Educação Ambiental, na Revista Brasileira de Educação Ambiental. Revista Brasileira de Educação Ambiental (RevBEA), v. 13, n. 3, p. 316-333, 2018. Disponível em:

< https://periodicos.unifesp.br/index.php/revbea/article/view/2605/1623 > Acesso em: 22 de mar 2019.

LIMA, Aguinel Messias de; OLIVEIRA, Haydée Torres de. A (re) construção dos conceitos de natureza, meio ambiente e educação ambiental por professores de duas escolas públicas. Ciênc. educ. (Bauru), Bauru, v. 17, n. 2, p. 321-337, 2011. Disponível em: < http://www.scielo.br/scielo.php?script=sci arttext\&pid=S151673132011000200005\&lng=en\&nrm=iso >. Acesso em: 23 Mar. 2019.

MACHADO, Aniara Ribeiro; MARQUES, Carlos Alberto; SILVA, Rejane Maria Ghisolfi da. Sentidos e significados de problema e problematização em um processo de (re)planejamento coletivo de uma situação de estudo. Ciênc. educ. (Bauru), Bauru, v. 22, n. 1, p. 23-42, Mar. 2016. Disponível em:

< http://www.scielo.br/scielo.php?script=sci arttext\&pid=S151673132016000100023\&lng=en\&nrm=iso >. Acesso em: 23 Mar. 2019. 
MAGALHAES JUNIOR, Carlos Alberto de Oliveira; TOMANIK, Eduardo Augusto.

Representações sociais de meio ambiente: subsídios para a formação continuada de professores. Ciênc. educ. (Bauru), Bauru, v. 19, n. 1, p. 181-199, 2013. Disponível em:

$<$ http://www.scielo.br/scielo.php?script=sci arttext\&pid=S1516-

73132013000100013\&lng=en\&nrm=iso >. Acesso em: 23 Mar. 2019.

MARTINS, José Pedro de Azevedo; SCHNETZLER, Roseli Pacheco. Formação de professores em educação ambiental crítica centrada na investigação-ação e na parceria colaborativa. Ciênc. educ. (Bauru), Bauru, v. 24, n. 3, p. 581-598, Sept. 2018. Disponível em: $<$ http://www.scielo.br/scielo.php?script=sci arttext\&pid=S151673132018000300581\&lng=en\&nrm=iso $>$. Acesso em: 23 Mar. 2019.

MENDES, Regina; VAZ, Arnaldo. Educação Ambiental no ensino formal: as narrativas de suas experiências e perspectivas. Educ. rev. Belo Horizonte, v. 25, n. 3, p. 395-411, dez. 2009. Disponível em < http://www.scielo.br/scielo.php?script=sci arttext\&pid=S010246982009000300019\&Ing=en\&nrm=iso >. Acesso em: 23 de março de 2019.

NIGRO, Rogério Gonçalves; AZEVEDO, Maria Nizete. Ensino de ciências no fundamental 1: perfil de um grupo de professores em formação continuada num contexto de alfabetização científica. Ciênc. educ. (Bauru), Bauru, v. 17, n. 3, p. 705-720, 2011. Disponível em < http://www.scielo.br/scielo.php?script=sci arttext\&pid=S151673132011000300012\&Ing=en\&nrm=iso >. Acesso em: 23 Mar. 2019.

PICCININI, Cláudia Lino. O discurso sobre a consciência em memoriais de educadores ambientais. Ciênc. educ. (Bauru), Bauru, v. 17, n. 3, p. 679-692, 2011. Disponível em $<$ http://www.scielo.br/scielo.php?script=sci arttext\&pid=S151673132011000300010\&lng=en\&nrm=iso >. Acesso em 23 MAR. 2019.

OBARA, Ana Tiyomi et al. Environmental education in the Upper Paraná River floodplain, municipality of Porto Rico (Paraná State), Brazil. Braz. J. Biol. São Carlos, v. 69, n. 2, supl. p. 627-635, junho de 2009. Disponível em $<$ http://www.scielo.br/scielo.php?script=sci arttext\&pid=S1519$\underline{69842009000300017 \& \operatorname{lng}=e n \& n r m=i s o}$ >. Acesso em 23 de março de 2019.

OBARA, Ana Tiyomi et al. Environmental education for sustainable management of the basins of the rivers Pirapó, Paranapanema III and Parapanema IV. Braz. J. Biol. São Carlos, v. 75, n. 4, supl. 2, p. 137-147, dezembro de 2015. Disponível em $<$ http://www.scielo.br/scielo.php?script=sci arttext\&pid=S1519$\underline{69842015000900137 \& \operatorname{lng}=e n \& n r m=i s o}$ >. Acesso em 23 de março de 2019. 
PELEGRINI, Djalma Ferreira; VLACH, Vânia Rúbia Farias. As múltiplas dimensões da educação ambiental: por uma ampliação da abordagem. Soc. nat. (Online), Uberlândia, v. 23, n. 2, p. 187-196, AGO. 2011. Disponível em <http://www.scielo.br/scielo.php?script=sci arttext\&pid=S1982$45132011000200003 \& \operatorname{lng}=e n \& n r m=i s o$ > . Acesso em 23 Mar. 2019.

REIGOTA, Marcos. O estado da arte da pesquisa em educação ambiental no Brasil. Pesquisa em educação ambiental, v. 2, n. 1, p. 33-66, 2007. Disponível em: <http://www.periodicos.rc.biblioteca.unesp.br/index.php/pesquisa/article/download/6130/ 4491 > Acesso em: 22 de mar 2019.

REIGOTA, Marcos. O que é educação ambiental. São Paulo: Brasiliense, 2009.

SANTOS, Vânia Maria Nunes dos; JACOBI, Pedro Roberto. Formação de professores e cidadania: projetos escolares no estudo do ambiente. Educ. Pesqui., São Paulo, v. 37, n. 2, p. 263-278, Aug. 2011. Disponível em:

$<$ http://www.scielo.br/scielo.php?script=sci arttext\&pid=S1517$\underline{97022011000200004 \& \operatorname{lng}=e n \& n r m=i s o}>$. Acesso em 23 Mar. 2019.

SAUVÉ, Lucie. Uma cartografia das correntes em educação ambiental. In: Sato, Michèle; Carvalho, Isabel Cristina de Moura (orgs) Educação Ambiental: pesquisa e desafios. Porto Alegre, Artmed, 2008.

SILVA, Rosana Louro Ferreira. Leitura de imagens da mídia e educação ambiental:

contribuições para a formação de professores. Educ. rev., Belo Horizonte, v. 26, n. 2, p. 277297, Aug. 2010. Disponível em:

< http://www.scielo.br/scielo.php?script=sci arttext\&pid=S0102$\underline{46982010000200013 \& \operatorname{lng}=e n \& n r m=i s o}>$. Acesso em 23 Mar. 2019.

TEIXEIRA, Catarina; ALVES, Jacqueline Magalhães. Mobilização do conhecimento socioambiental de professores por meio do desenvolvimento de ações para conservação de nascentes urbanas. Ens. Pesqui. Educ. Ciênc. (Belo Horizonte), Belo Horizonte, v. 17, n. 3, p. 769-792, Dec. 2015. Disponível em:

< http://www.scielo.br/scielo.php?script=sci arttext\&pid=S1983-

21172015000300769\&Ing=en\&nrm=iso >. Acesso em: 23 Mar. 2019.

TEIXEIRA, Cristina; TORALES, Marília Andrade. A questão ambiental e a formação de professores para a educação básica: um olhar sobre as licenciaturas. Educ. rev., Curitiba, n. spe3, p. 127-144, 2014. Disponível em:

< http://www.scielo.br/scielo.php?script=sci arttext\&pid=S0104$40602014000700009 \&$ Ing=en\&nrm=iso >. Acesso em: 23 Mar. 2019. 
TOZONI-REIS, Marília Freitas de Campos et al. A inserção da educação ambiental na Educação Básica: que fontes de informação os professores utilizam para sua formação? Ciênc. educ. (Bauru), Bauru, v. 19, n. 2, p. 359-377, 2013. Disponível em: < http://www.scielo.br/scielo.php?script=sci arttext\&pid=S151673132013000200009\&lng=en\&nrm=iso >. Acesso em: 23 Mar. 2019.

TOZONI-REIS, Marília Freitas de Campos; CAMPOS, Luciana Maria Lunardi. Educação ambiental escolar, formação humana e formação de professores: articulações necessárias. Educ. Rev., Curitiba, n. spe3, p. 145-162, 2014. Disponível em:

$<$ http://www.scielo.br/scielo.php?script=sci arttext\&pid=S0104$40602014000700010 \& \operatorname{lng}=\mathrm{en} \& \mathrm{nrm}=\mathrm{iso}$ >. Acesso em:

23 Mar. 2019.

TUAN, Yi-Fu. Topofilia: um estudo da percepção, atitudes e valores do meio ambiente. São Paulo: Difel, 1980.

TUAN, Yi-Fu. Paisagens do medo. São Paulo: Editora UNESP, 2005. 